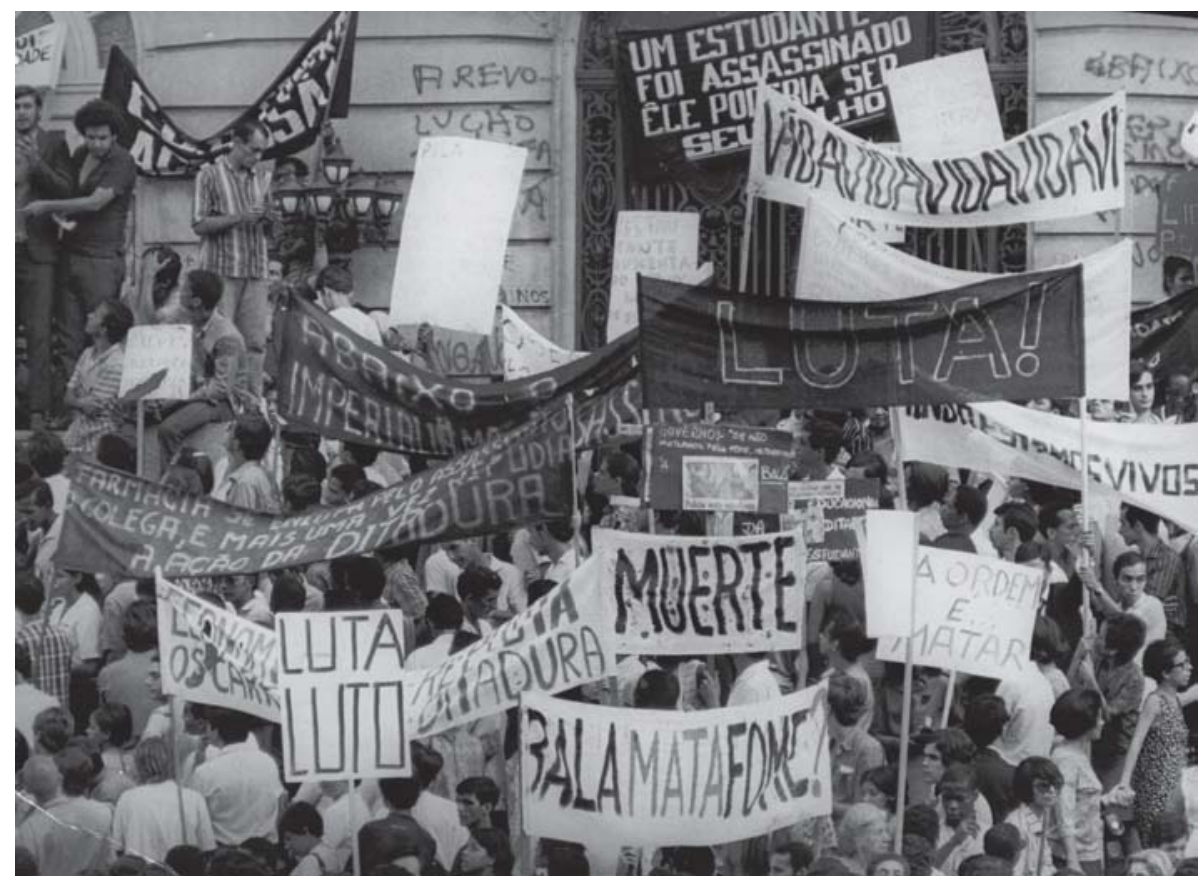

Manifestação em enterro de estudante. Rio de Janeiro. 1968. Correio da Manhã. 


\title{
La actividad de las
agrupaciones estudiantiles
maoístas entre la lucha
antidictatorial y el retorno
del peronismo
}

A atividade dos grupos de estudantes maoístas entre a luta anti-ditatorial e o retorno do peronismo

The activity of groups of Maoists students between the anti-ditatorial struggle and the return of Peronism

\section{Adrián Celentano*}

\begin{abstract}
Resumen- Desde mediados de los años sesenta, en el marco de la creciente radicalización política e ideológica que se registra en Latinoamérica, los jóvenes que estudian en las universidades argentinas fundan un conjunto de agrupaciones y frentes que participan en la lucha contra la dictadura militar encabezada por el general Juan C. Onganía. Un novedoso abanico de nuevas tendencias se disputaron la organización del movimiento estudiantil. Éstas se caracterizaron por romper con la izquierda tradicional (el Partido Comunista y el Socialista), por cuestionar las instituciones académicas y científicas de la época dominadas por el paradigma desarrollista y por participar de los movimientos insurreccionales de 1969-1971. El presente artículo mapea las agrupaciones estudiantiles vinculadas a los partidos y corrientes de la llamada "nueva izquierda", específicamente de cuatro agrupamientos maoístas de desiguales dimensiones.
\end{abstract}

Palabra clave: nueva izquierda; estudiantes; intelectuales; insurrecciones; maoísmo.

Resumo- Desde meados dos anos sessenta, sob crescente radicalização política e ideológica registrada na América Latina, os jovens que estudam nas universidades argentinas fundam várias frentes e grupos envolvidos na luta contra a ditadura militar, chefiada pelo general John C. Onganía. Uma gama inovadora de tendências se abateram sobre a organização do movimento. Estas foram caracterizadas por romper com a esquerda tradicional (do Partido Comunista e Socialista), por questionar as instituições acadêmicas e científicas da época, dominadas pelo paradigma do desenvolvimento, e por participar dos movimentos revolucionários de 1969 e 1971. Este artigo mapeia os grupos de estudantes ligados a partidos e correntes da "nova esquer$\mathrm{da}^{\prime \prime}$, especificamente quatro grupos maoístas de dimensões desiguais. Palavras-chave: nova esquerda; estudantes; intelectuais; insurreições; maoísmo.

\footnotetext{
* Profesor de Historia por Facultad de Humanidades y Ciencias de la Educación de la Universidad Nacional de La Plata (FaHCE-UNLP), Argentina, e doctorando en Historia de la FaHCE-UNLp. Profesor Titular de la cátedra "Historia social argentina y latinoamericana" de la Facultad de Trabajo Social (FTS) de la UNLP. Profesor Adjunto de la cátedra "Problemas de historia del pensamiento argentino y americano" de la FaHCE-UNLP. Investigador del Instituto de Investigaciones de Humanidades y Ciencias de la Educación (IDIHCS) del CONICET-UNLP. E-mail: <adriancelen tano@gmail.com>
} 


\begin{abstract}
Since the mid-sixties, in presence of the rise of the political and ideological radicalization in Latin-American, the young argentine universities students founded a series of fronts and groups involved in the struggle against the military dictatorship led by General Juan C. Onganía. An innovative range of trends competed for the organization of the student movement. They characterized by breaking with the traditional left (the Communist and the Socialist Parties) by questioning the academic and scientific institutions established controlled by the paradigm "desarrollista" of the development. Also by taking part in the revolutionary movements emerged between 1969 and 1971. This papers maps the student groups linked to parties and currents of the "New Left", specifically four Maoist groups of unequal dimensions.

Keywords: new left; students; intellectual; revolts; maoism.
\end{abstract}

\title{
Presentación
}

En agosto de 1971 la tapa de la revista cultural Los Libros emula un famoso afiche del mayo francés: un joven lanza una piedra que hace estallar un vidrio pero detrás de ese vidrio el interrogante que se deja ver es "¿Por qué Córdoba?". ${ }^{1}$ Esa insurrección protagonizada por la juventud estudiantil y los obreros a la que aluden las tapas de Los Libros condensa el cuestionamiento político que por esos años se escuchaba de París a Río de Janeiro y de Pekín a La Plata. Tres meses después, Los Libros elige como título "Universidad y lucha de clases". ${ }^{2}$ La foto de tapa muestra una universidad que no puede ser el eje del proyecto revolucionario, pues el gran aula vacía con el cartel "Presidente honorario: Che Guevara" sugiere que, bajo ese liderazgo, los estudiantes alineados con la nueva izquierda han salido de la universidad para participar de la lucha callejera contra la dictadura militar instaurada desde junio de 1966 (TORTTI, 1999). Como veremos, la imagen y el título de este nuevo número condensan la posición de la revista sobre el momento político, esto es, la importancia de la participación universitaria en la "secuencia acontecimental" que habría abierto Mayo de 1969 - y que veremos que se cierra con el golpe de Estado de 1976. (BADIOU, 2010, p. 76).

A comienzos de los setenta, el comité editorial de Los Libros estaba formado por un pequeño grupo de intelectuales vinculados a Vanguardia Comunista (VC) y el Partido Comunista Revolucionario (PCR), los dos partidos maoístas más conocidos de la época. Además de integrar el amplio abanico de la nueva izquierda universitaria (que incluía a las tendencias revolucionarias del peronismo como Montoneros y las Fuerzas Armadas Peronistas; a las diversas expresiones del troskismo y del guevarismo como

\footnotetext{
${ }^{1}$ Los Libros, 21, agosto de 1971. La revista Los Libros aparece en julio de 1969, bajo la dirección de Héctor Schmucler, y es cerrada en marzo de 1976. La revista tuvo distribución nacional e internacional, tiraba más de mil ejemplares por bimestre. Ver Celentano, 2007, p. 1.

${ }^{2}$ Los Libros, 23, noviembre de 1971.
} 


\section{ReVistg all PaVtg}

\} LA ACTIVIDAD DE LAS AGRUPACIONES - CELENTANO, A. \}

el Partido Revolucionario de los Trabajadores-Ejército Revolucionario del Pueblo), los agrupamientos estudiantiles alineados con los mencionados partidos maoístas jugaron un rol destacado - y poco recordado - en la lucha universitaria contra la dictadura. Estos grupos juveniles, integrados por jóvenes de clases medias bajas, provenían de rupturas con los viejos partidos Socialista y Comunista y disputaban la dirección del movimiento estudiantil a las tendencias humanistas moderadas, como el Integralismo, y a la Franja Morada, brazo universitario de la Unión Cívica Radical.

El 1966 el gobierno del general Juan Carlos Onganía intervino las universidades estatales, a las que entendía como un foco de agitación comunista. ${ }^{3}$ En julio de ese año la Policía Federal irrumpió violentamente en diversas facultades de la Universidad de Buenos Aires (UBA), en lo que se denominó la "Noche de los bastones largos". En el interior del país las protestas estudiantiles impulsadas por los centros y federaciones fueron duramente reprimidas, y en Córdoba durante una movilización callejera que contó con dos mil manifestantes fue asesinado el estudiante Santiago Pampillón. Las principales políticas impulsadas por los militares fueron la intervención a las universidades (con la consiguiente desaparición de la autonomía universitaria, el cogobierno, el régimen de concursos, las libertades de agremiación, de reunión y de uso de la palabra); la imposición de aranceles y exámenes de ingreso, medidas Ilamadas "limitacionistas" porque buscaban la reducción de la matrícula universitaria (matrícula que también se planeaba descentralizar geográficamente), además de los aumentos en los tickets de los comedores universitarios. Este conjunto de medidas gubernamentales eran caracterizadas por el movimiento estudiantil como "Universidad de la dictadura" (BUCHBINDER, 2005; CALIFA, 2014).

Los dos grupos estudiantiles más numerosos del maoísmo fueron: la Tendencia Universitaria Popular Antimperialista y Combativa (TUPAC), ligada a VC, y el Frente de Agrupaciones Universitarias de Izquierda (FAUDI), brazo estudiantil del PCR. A estas fuerzas se sumaron algunos grupos estudiantiles más pequeños surgidos en 1971: el Grupo de Estudiantes Antiimperialistas (GEA), alineado con el Partido Comunista Maoísta (PCM), y los Grupos de Resistencia Estudiantil (GRE), organización universitaria impulsada por el Partido Comunista Marxista Leninista (PCML).

Entre 1968 y 1971 la TUPAC y el FAUDI lograron participar de la dirección de la Federación Universitaria Argentina (FUA), así como de la dirección de varias federaciones regionales y centros estudiantiles (ORBE, 2010). Desde esa ubicación estratégica ambas agrupaciones impulsaron en junio de 1968 (año del cincuenta aniversario de la Reforma Universitaria de 1918) una importante huelga estudiantil con movilizaciones en todo el

${ }^{3}$ El general Juan C. Onganía derrocó al gobierno de Arturo Illia, perteneciente a la Unión Cívica Radical, el 28 de junio de 1966, dando inicio a lo que se llamó "Revolución Argentina" que impuso en 1966 una forma dictatorial de gobierno, Ilamada por O’Donnel "estado burocrático autoritario" (1982). 


\section{Revista pll paעtg}

\} LA ACTIVIDAD DE LAS AGRUPACIONES - CELENTANO, A. \}

país, y protagonizaron los movimientos insurreccionales que se registraron por esos años: el Correntinazo, el Rosariazo, el Cordobazo y el Tucumanazo (CRENZEL, 1991; RAMIREZ, 2008). Pero 1972 marca un corte en esa secuencia insurreccional y se interrumpe aquel protagonismo. En mayo de 1973 el peronismo retorna al poder, primero con la victoria electoral de Héctor J. Cámpora, alineado con la tendencia revolucionaria del peronismo y luego con la elección de Juan D. Perón como presidente. Entre ese año y 1974 la actividad de la TUPAC y el FAUDI, así como la de otras corrientes izquierdistas, es eclipsada por el ascenso del peronismo universitario, y luego por la "Misión Ivanissevich" (1974-1975), intervención que pone a la universidad en manos de la derecha peronista. Y 1976 marca un nuevo escenario, púes la dictadura militar declara como subversivos a los grupos maoístas junto a otras tendencias de la nueva izquierda. A pesar de la persecución política varios grupos intentan seguir actuando en la clandestinidad y sufren la dura represión que desata la dictadura.

El presente artículo pretende mapear el recorrido que realizan entre 1968 y 1976 las agrupaciones estudiantiles durante la dictadura militar se identifican con las tesis maoístas. En su estudio de la relación entre estudiantes y política, Juan Carlos Portantiero considera que el movimiento estudiantil es una "fuerza intelectual en proceso de formación" (PORTANTIERO, 1978, p. 28). Esa definición junto a la atención a tres tipos de prácticas militantes nos ayudará a establecer los rasgos específicos de las corrientes estudiantiles maoístas argentinas. Una de las prácticas militantes a la que atenderemos es la politización, en la que está involucrada tanto la radicalización teórico-política que implica la ruptura con la tradición universitaria socialista y comunista, como las invenciones en las aulas (de nuevas relaciones con los docentes y entre los estudiantes), en las estructuras organizativas del movimiento y en la relación entre estudiantes y campo intelectual. Otra práctica militante que relevaremos es la partidización; allí englobamos: las prácticas organizativas que reformulan el tipo de Partido al que aspiran las corrientes maoístas, los nexos que ese partido plantea entre los estudiantes y los modelos insurreccionales, y los posicionamientos sobre la lucha militar. La tercera y última práctica militante en que nos concentraremos es la proletarización, agregado de experiencias que tienen como objetivo la fusión de la teoría y la práctica pregonada por el maoísmo y que, amparadas en la consigna "unidad obrero-estudiantil", promovieron la problemática inserción de los militantes de origen universitario en las fábricas (CELENTANO, 2009).

Por otra parte, en el periodo recortado creemos poder distinguir tres fases. La primera estaría dominada por la irrupción generalizada de masas, la insurrección como acontecimiento (1968-1971); la segunda estaría marcada por la estatización, pues prima la capacidad estatal de absorber las rupturas producidas por el ciclo insurreccional (1972-1974); y en la tercera primaría el "estado de excepción", pues el estado y grupos paraes- 


\section{ReVistg all paUtg}

\} LA ACTIVIDAD DE LAS AGRUPACIONES - CELENTANO, A. \}

tatales desatan una violenta represión sobre el movimiento estudiantil (19741976), (FRANCO, 2011).

Con este mapa buscamos contribuir al estudio de las formas específicas en que esas corrientes estudiantiles incidieron en la coyuntura revolucionaria que convulsiona a la sociedad argentina desde 1969. Asimismo, nuestro mapa pretende ofrecer una nueva mirada de las concepciones políticas emancipatorias y los límites que encontraron estos grupos universitarios al intentar ponerlas en práctica.

\section{1- TUPAC}

La estructuración de la TUPAC fue el resultado de la militancia estudiantil de VC. Este grupo surge en 1965 de una ruptura producida en el Partido Socialista de Vanguardia (PSV) (TORTTI, 2009; CELENTANO, 2011). Allí se encuentran numerosos cuadros estudiantiles que en 1969 fundan la TUPAC bajo la dirección de Lelel Horane y Jorge Montero. El primer comité central de VC estuvo compuesto por estudiantes y graduados universitarios: el secretario general, Elías Semán, había sido dirigente estudiantil en la Facultad de Derecho de la UBA y el secretario de organización, Roberto Cristina, había estudiado sociología en la misma universidad (TARCUS, 2007). Antes de la fundación de VC, ambos jóvenes militaban en el PSV, partido aliado de la revolución cubana y al peronismo. Pero la sucesión de "claudicaciones" de la dirección sindical y política peronista ante los militares y los empresarios lleva a esos jóvenes a criticar la posición de PSV, con el que rompen en 1965 para fundar VC, el primer grupo argentino que se reivindica maoísta.

Dentro de la izquierda universitaria, los maoístas argentinos criticaron al PC argentino la subordinación de la línea del frente universitario a la política del frente democrático, pues allí se encubriría un modo de reemplazar con la burguesía nacional la pérdida del apoyo obrero. Por otra parte, acusaban al PC de ampararse en la reivindicación de la Reforma del 18 para negar al movimiento estudiantil el camino de la lucha revolucionaria. En ese sentido, los maoístas se distanciaban de una línea política que consideraban que no era más que el reflejo de la subordinación de los comunistas argentinos a los intereses de los "revisionistas" soviéticos.

Desde 1966 los primeros maoístas construyen agrupaciones en los centros y federaciones de las universidades estatales, intervenidas por el gobierno militar encabezado por el general Onganía; en 1968 consiguen participar de la dirección de la Federación Universitaria Argentina (FUA) y en 1969 tienen una intervención destacada en el Cordobazo. Días antes del estallido cordobés, difundían volantes en los que convocaban a "organizarse por abajo, en comisiones de resistencia por curso", organismos pensados como poleas de transmisión de la voluntad estudiantil a la 


\section{Revista pll paעtg}

\} LA ACTIVIDAD DE LAS AGRUPACIONES - CELENTANO, A. \}

dirección de los centros para participar en "la gran batalla contra la dictadura". ${ }^{4}$ Luego del Cordobazo, los maoístas insistían en que esas jornadas desbordaron a las organizaciones estudiantiles preexistentes y que, esencialmente, las luchas tuvieron un carácter espontáneo. A partir de este acontecimiento político, los maoístas promueven una ruptura con el modelo organizativo de la tradición de la Reforma Universitaria que sostenían las agrupaciones estudiantiles mayoritarias, esto es, buscan pasar el poder que hasta entonces residía en el centro estudiantil único a la asamblea estudiantil de masas. La asamblea debía devenir el espacio deliberativo por excelencia. Si bien se trataba de una práctica de democracia directa, los grupos maoístas buscaron que en la asamblea se expresen los delegados de cursos, pues esta organización ayudaría a masificar las asambleas y a movilizar a los estudiantes más allá de la convocatoria de los centros de estudiantes. Por otra parte, los maoístas proponían que en esas asambleas fueran electos los delegados que se enviarían a los centros regionales, centros con los que se esperaba organizar una dirección central única de los universitarios (recordemos que la FUA se encontraba dividida desde hacía casi diez años, FERRERO, 2009, MILLAN, 2013). En 1971 la TUPAC y otras fuerzas estudiantiles lograron llevar a la práctica este sistema, conocido como la experiencia de los "cuerpos de delegados" en la Facultad de Filosofía y Letras de la UBA (BONAVENA, 1997).

A pesar de sus líneas políticas encontradas, las distintas tendencias que nutrían la nueva izquierda - la TUPAC entre ellas - creyeron encontrar en el Cordobazo y el clasismo obrero la confirmación de sus tesis (GORDILLO y BRENNAN, 2009). A punto tal que los maoístas exaltan por medio de panfletos, folletos y periódicos que los obreros dirigen y elevan la combatividad estudiantil, como registra el epígrafe de este apartado, referido al levantamiento tucumano. Otra muestra de ello es el análisis de TUPAC sobre el multitudinario "Encuentro entre de intelectuales y estudiantes", convocado en 1970 por la Corriente de Izquierda Universitaria (CIU) 29 de Mayo, agrupamiento frentista impulsado por el PCR.

Análisis que permite dar cuenta del posicionamiento de TUPAC sobre la coyuntura política; $y$, además, manifiesta las tensiones en su relación con los convocantes, la CIU en el momento en que el brazo estudiantil del PCR reunía mayor número de militantes y se inclinaba progresivamente hacia las posiciones maoístas.

TUPAC criticó el título del encuentro, "Ciencia e Ideología", por su carácter abstracto, al tiempo que celebró el hecho de que la discusión haya forzado la retirada de intelectual nacionalista de izquierda, Jorge Abelardo Ramos, y denunció que los intelectuales "pseudo marxistas" que animaban el proyecto "Marginalidad" se Ilamaron a silencio cuando en una sesión de encuentro se discutió el rol del intelectual en la revolución. A

4 "Universidad: impulsar la lucha de masas", No Transar, 77, 18 de abril de 1969, p. 21-22. 


\section{ReVistg all paUtg}

\} LA ACTIVIDAD DE LAS AGRUPACIONES - CELENTANO, A. \}

todos ellos, los maoístas de TUPAC les contraponen la intervención de la flamante conducción obrera clasista del Sindicato de Trabajadores de Concord (SITRAC) que marcó el punto de inflexión del encuentro porque los estudiantes junto a los obreros clasistas impusieron el "análisis concreto de la situación concreta": la emergencia de la vanguardia revolucionaria obrero-estudiantil en "la forja" de la ciudad mediterránea. ${ }^{5}$ Esta fuerza emergente es la verdadera vanguardia para TUPAC, más allá de las representaciones de los organismos de masas. De allí que los maoístas fueran frecuentemente acusados por otros de "espontaneístas".

Por último, la politización impulsada por la TUPAC cordobesa afecta los instrumentos académicos, como se manifestó en la experiencia de Taller Total, de la Facultad de Arquitectura. Esta experiencia, que formó parte de un intenso movimiento de los estudiantes y docentes de Arquitectura en otras universidades (La Plata, Rosario y Tucumán), reformuló los planes de estudio, la relación entre docentes y estudiantes; entre los universitarios y las necesidades de los sectores populares, y ganó amplia repercusión entre los intelectuales. En efecto, el aula vacía que ocupa la tapa de la revista Los Libros citada más arriba, es el aula magna de la Facultad de Arquitectura de Córdoba, cuyo centro de estudiantes era conducido por un frente en que las principales fuerzas eran el FAUDI y la TUPAC.

Un año después la TUPAC, el FAUDI y una extensa estela de agrupaciones unifican sus reivindicaciones, convocan al $1^{\circ}$ Encuentro $\mathrm{Na}$ cional de Estudiantes que formula un plan de lucha con el objetivo de converger con la protesta obrera para derrocar a la dictadura (ahora encabezada por el general Levigston) y a la vez reconstituir la FUA con una línea "revolucionaria" y "antimperialista".

La construcción del partido es visualizada por VC, entre 1965 y 1976, como la herramienta imprescindible para dotar de una dirección al movimiento revolucionario. Sea para fundar un partido unificado con el PCR o para erigirse en "vanguardia" o "estado mayor proletario", de lo que se trata para VC es de consolidar una estructura organizativa que pueda ser independiente tanto de la dirección peronista como de la creciente acción de las organizaciones guerrilleras, con las cuales discrepan.

En 1969, VC organiza su primer congreso (que finalmente se realizó en 1971) la mayoría de los delegados elegidos provenía de la militancia universitaria. El anteproyecto redactado para la discusión en ese congreso la construcción de un Partido "marxista-leninista" que debería enraizarse en la clase obrera y el campesinado. Ese documento también asigna importantes tareas revolucionarias a los estudiantes, los intelectuales y las clases medias. Por entonces prácticamente todas las regionales tuvieron en su comité de dirección a estudiantes avanzados, profesionales y docentes, aunque también poblaron esos comité, en menor proporción, obreros (al-

5 "Encuentro entre intelectuales y estudiantes", en No Transar, 90, octubre de 1970, p. 4. 


\section{Revista pll paעtg}

\} LA ACTIVIDAD DE LAS AGRUPACIONES - CELENTANO, A. \}

gunos provenientes de la experiencia del Socialismo de Vanguardia, otros que rompían con el PC y otros provenientes del peronismo).

Pocos días después del Cordobazo, $\mathrm{VC}$ reitera su decisión de constituir el Partido e inserta en una declaración política un párrafo significativo por su dimensión pedagógica: "Ese Estado Mayor debe ser [...] [VC], hijo y alumno del proletariado y a la vez, su maestro y guía" (No Transar, 80, 1969 , p. 7). Era poca la exageración de estas metáforas pues las regionales partidarias, reconocidas por su participación en los movimientos insurreccionales, fueron constituidas a partir del desarrollo de frentes estudiantiles o de la inserción de universitarios en movimientos sindicales.

Por ejemplo, en Mendoza los debates que se dan al interior de VC sobre la insurrección de 1972, el apoyo crítico al gobernador Martínez Baca en 1973, la postura sobre la acción de los aparatos represivos del estado y sobre la acción de las organizaciones guerrilleras, tienen como protagonistas a los militantes reclutados por la TUPAC. Las circulares y documentos organizativos de la VC mendocina buscan, entre otros objetivos, consolidar la construcción partidaria, evitar que los activistas universitarios subordinen la militancia estudiantil a la lógica académica o a los requerimientos familiares y resguardar la inserción de esa militancia entre las masas juveniles. Un reciente texto de carácter militante, registra - y a la vez refrenda - la importancia del nexo entre frente estudiantil y construcción partidaria en esa provincia. Ya en el primer párrafo de la crónica afirma

TUPAC fue el inicio de la actividad, de la práctica y de la inserción de masas de Vanguardia Comunista en Mendoza. Si bien VC fue fundada allí en 1965, recién en 1969 las raíces sembradas por Fuad Toum comienzan a dar frutos importantes. Y esto se inició en la Facultad de Medicina de la Universidad Nacional de Cuyo. (ESPINOSA, 2010, p. 156)

Además, la proletarización como método de formación de cuadros incidió más en el perfil del militante partidario que la inserción de VC en los movimientos de masas. Un proceso similar ocurrió en otras regionales. Por ejemplo, varias experiencias de proletarización impulsadas en Buenos y Aires, como la de Graciela Lo Prete en la metalúrgica Epsilon, desembocaron en fuertes decepciones por parte de los militantes, que no lograban concretar el modelo de transformación individual e inserción sindical anhelada en las iniciales propuestas. En otros casos, como la proletarización protagonizada por Jorge Weiss y Carlos Patrignani en el ingenio azucarero Ledesma, provincia de Jujuy, los militantes se insertaron entre los trabajadores, alcanzaron puestos de dirección en la movilización popular, organizaron el comité partidario y ganaron reconocimiento público para VC (CELENTANO, 2009).

Las insurrecciones del '69 en Córdoba, Rosario y Tucumán, constituyen para esas regionales de VC la validación en el terreno organizativo 


\section{ReVistg all paUtg}

\} LA ACTIVIDAD DE LAS AGRUPACIONES - CELENTANO, A. \}

de la proletarización estudiantil porque contribuye a la inserción partidaria entre las masas, amplificada por la expansión del clasismo entre las bases obreras a nivel nacional. Podemos señalar que en 1970 la emergencia de los sindicatos clasistas Sitrac-Sitram guarda un estrecho vínculo con estas organizaciones políticas integradas mayoritariamente por jóvenes universitarios. Al mismo tiempo, como subrayan los volantes y las revistas de la época, las multitudinarias asambleas estudiantiles en la puerta de las fábricas durante las tomas y las ocupaciones fabriles, aporta a la rebeldía obrera una nueva fuerza en la confrontación con las patronales y el gobierno. El protagonismo de las rebeldes bases obreras en los procesos insurreccionales operará en la TUPAC -y en los otros grupos maoístas- como argumento para justificar la toma de distancia tanto respecto del peronismo, por su integración en la salida electoral de 1973, como de la acción de las organizaciones político militares (especialmente Montoneros y el Partido Revolucionario de los Trabajadores - Ejército Revolucionario del Pueblo PRT-ERP), empeñadas en la construcción de los ejércitos revolucionarios. Sin embargo, cabe subrayar que la TUPAC tendrá, en diferentes regionales, desprendimientos de cuadros estudiantiles que emigrarán a las organizaciones de la izquierda peronista.

Durante el gobierno de Campora, la TUPAC brindará su apoyo a Rodolfo Puiggrós, el interventor que los Montoneros impulsaron en la UBA, y a los otros interventores afines a esa tendencia peronista, como los de La Plata, Tucumán y Cuyo. Además compartirá con la Juventud Universitaria Peronista varias iniciativas en la lucha contra el ala derecha del peronismo universitario. Las divergencias de la TUPAC con los Montoneros afloraban en el debate de cuestiones ideológicas como las referidas al populismo o al rol de Perón y se tornaban candentes a la hora de definir los métodos de lucha del movimiento estudiantil cuando la organización Montoneros pasó a la clandestinidad.

\section{2- El FAUDI}

La formación del PCR tiene su origen en la escisión, producida en enero de 1968, de la dirección de la Federación Juvenil Comunista (FJC) (BREGA, 1990, GILBERT, 2009). El frente universitario que integraba buena parte de la FJC y que estaba encabezado por el presidente de la FUA, Jorge Rocha, acusa de "reformista" y luego de "revisionista" a la dirección del PC, con la que había roto. En el seno del nuevo partido se produce una intensa discusión político-ideológica: el PCR pasa de sus iniciales posturas cercanas al guevarismo a la adopción del maoísmo. En la universidad, el PCR estructura el FAUDI como su frente de masas, articulado en una corriente de alcance nacional, con presencia en la mayoría de los centros y federaciones regionales que intervienen en los movimientos insurreccio- 


\section{Revista pll paעtg}

\} LA ACTIVIDAD DE LAS AGRUPACIONES - CELENTANO, A. \}

nales. En la constitución de este frente universitario izquierdista confluye el Movimiento Estudiantil Nacional de Acción Popular (MENAP), que era una escisión del MNR y estaba dirigido por Ariel Seoane. Según Vargas, contaba "con líderes de masas en las principales universidades del país, [...] dirigía importantes centros y federaciones (BREGA, 1990, p. 30-31). Al mismo tiempo, ese frente universitario proporciona al partido, sobre todo en su periodo de construcción (1968-1971), los cuadros de la mayoría de sus organismos de dirección.

Para analizar al FAUDI elegimos el artículo "El movimiento estudiantil de la Reforma al Cordobazo", publicado en la revista Los Libros, en su célebre número dedicado a Córdoba, y firmado por Osvaldo Reics y Ramón Cuevas, seudónimos de dos jóvenes intelectuales alineados con PCR: Antonio Marimón y Horacio Crespo. Crespo provenía del grupo Pasado y Presente y Marimón, graduado de letras, era el redactor de la propaganda clasista del PCR para los obreros mecánicos (BURGOS, 2005; CRESPO, 2009). El artículo citado aborda acontecimientos histórico-político nacionales desde una posición coincidente con el documento titulado "Bases para el primer congreso del FAUDI", elaboradas en septiembre de 1971, y con varios de los panfletos difundidos por las regionales del FAUDI por esos años. De ahí que la nota nos permita reponer la línea política del FAUDI, pero además, al abarcar un amplio periodo (1945-1971), puede ser usada como una vía privilegiada para explicitar la clave histórica impulsada por el frente estudiantil, así como para identificar las limitaciones y los problemas que encontraba la política del FAUDI en el desarrollo del movimiento estudiantil y en la escena política al finalizar el bienio rojo (mayo de 1969-octubre de 1971).

En primer término, el artículo revela dos cuestiones poco analizadas en los estudios sobre el movimiento estudiantil. Por un lado, es significativo que un análisis del movimiento estudiantil como el propuesto en el artículo de Reics y Cuevas (en adelante RyC) le asigne tanta importancia al FAUDI, sobre todo en la Córdoba rebelde. Por otro, debe atenderse a que ese análisis haya sido publicado junto con otro, aparecido en el mismo número, que informa rigurosamente sobre los sindicatos Sitrac-Sitram y destaca la relación de los gremios clasistas con el movimiento estudiantil, pues ambos textos revelan nexos bastante estrechos entre el FAUDI y un grupo clave de la nueva izquierda intelectual como lo era el agrupado en Los Libros.

Los autores inician su artículo saludando el hecho de que el movimiento estudiantil haya roto con el legado de la Reforma Universitaria. Al abordar el Manifiesto Liminar de 1918, advierten RyC:

Hoy el abogado cordobés Gustavo Roca, amigo del Che Guevara e hijo de Deodoro Roca - un prócer de la Reforma - prefiere afirmar: "La Reforma fue todo lo que pudo ser. No pudo ser más de lo que fue, en drama y en protagonistas. Dio de sí todo. Y dio pronto con sus lí- 


\section{nevistg ell palla}

\} LA ACTIVIDAD DE LAS AGRUPACIONES - CELENTANO, A. \}

mites infranqueables, los que le señalaba su propio carácter pequeñoburgués" (Los Libros, 21, 1971, p. 17).

Reconociendo la necesidad de ir más allá de la Reforma, los autores afirman que el modelo del centro único sería parte del "liberalismo democrático" que caracterizó al reformismo. Desde 1945 ese modelo habría estado amenazado por la "superestructura facistoide" del peronismo en la universidad, es por ello que el estudiantado se habría enfrentado con el proletariado peronista convirtiéndose en "una fábrica de cuadros gorilas" hasta 1955. Tres años después el movimiento estudiantil lucha masivamente contra el artículo 28 de la ley de Frondizi que habilitó la enseñanza privada. Según el texto, esa lucha facilitó el olvido de la guerra de los estudiantes contra el peronismo y renovó las herencias políticas que dieron luz al movimiento estudiantil moderno. Aquella batalla también se habría cristalizado en la ruptura de la FUA de 1959, escisión impulsada por la Franja Morada desde la Federación Universitaria platense.

En los mismos años, el estudiantado cordobés estaba orientado, sobre todo, por la corriente "Integralista" (inicialmente inspirada en concepciones católicas y luego volcada hacia el peronismo), el Movimiento Nacional Reformista (MNR; ligado al socialismo), el MUR (alineado con el PC), la Agrupación Universitaria Nacional (AUN; ligada al citado Jorge Abelardo Ramos) y la "izquierda independiente" (liderada por Abraham Kosak). Esta izquierda, que ganará la dirección de la federación local a mediados de los sesenta, había trabado un estrecho lazo con el grupo de intelectuales de la revista Pasado y Presente, grupo liderado por el intelectual José Aricó, que el artículo de RyC reivindica por su castrismo, policentrismo a lo Togliatti y por su renovación del leninismo. Los autores enfatizan que esa tendencia de la izquierda cordobesa es la que había enfrentado más decididamente al PC: en el congreso de la FUA de 1965 le cuestiona su antiperonismo, al tiempo que postula la lucha armada como vía revolucionaria y al Che Guevara como comandante. Recordemos que en 1969 una parte de los jóvenes ligados al grupo pasadopresentista, entre ellos Santiago Funes y Horacio Crespo, dejan ese grupo para integrarse al PCR.

Continuando con el artículo, RyC sostienen que en 1966, en la gran batalla cordobesa contra la intervención de la universidad, la dirección estudiantil quedó en manos del Integralismo junto con el Movimiento de Liberación Nacional. Ambas fuerzas lograron imponerse sobre la izquierda independiente en una asamblea gigantesca en la que lanzaron la huelga general por tiempo indeterminado. Aunque el texto califica a esta medida de "suicida", reconoce que funcionó como un importante antecedente del Cordobazo: en 1966 los estudiantes tomaron la audaz decisión de sacrificar su acuerdo con el cuerpo docente aliado para iniciar una movilización callejera; esta movilización centrada en la defensa del reformismo universitario los enfrentó violenta y dramáticamente con la policía. Para 


\section{hevigta all pgutg}

\} LA ACTIVIDAD DE LAS AGRUPACIONES - CELENTANO, A. \}

RyC, esta derrota cierra un ciclo que recién se reabre en 1969 con la búsqueda programática de alianzas con el proletariado.

RyC critican a los grupos que integraban la "línea nacional" (Integralismo, Agrupación Universitaria Nacional, ligada a la izquierda nacional y Frente Estudiantil Nacional (FEN), grupo de la izquierda peronista) por sus vacilaciones políticas y sobre todo su tendencia a subordinarse a Perón y al Gran Acuerdo Nacional (GAN) que impulsaba el general Lanusse. Los autores realizan críticas similares al bloque "liberal", que en 1970 controlaba los centros estudiantiles de las facultades de Derecho y Ciencias Económicas y estaba integrado por FM, el MNR y el PC. Este bloque es cuestionado por su alineación con partidos integrados en el GAN. En esas definiciones del artículo se descubre una clara convergencia de los autores con la línea del FAUDI.

Por otro lado, en su reconstrucción histórica RyC oponen la frustración de 1966 al auge de la rebelión estudiantil correntina y rosarina de mayo de 1969, detonadora en Córdoba de un "espontaneo movimiento de deliberación por cursos" que comienza a oponerse a la "Coordinadora Estudiantil de Lucha" (hegemonizada por el Integralismo y el FEN). Aquella espontaneidad se radicaliza en las facultades de Arquitectura, Artes y Filosofía; en junio de ese año una asamblea de nueve mil asistentes -en la que emerge una nueva tendencia: el bloque de izquierda- toma distancia del Integralismo y el FEN, adopta un perfil más contestatario y cuestiona a la Coordinadora por burocrática. Si bien la tendencia nacional retiene la conducción de algunos centros de estudiantes cordobeses, la nueva política que irrumpe en la asamblea puede ser asociada a la apertura de una nueva secuencia, que ha logrado instalarse gracias a las invenciones organizativas realizadas, entre otros, por los grupos maoístas que aquí estudiamos.

Como era de esperar, RyC destacan la formación de un tercer bloque, el de la izquierda cordobesa, encabezado por el FAUDI, que conduce el centro de Filosofía y Letras aliado con la Línea de Acción Popular (LAP; asociada al populismo de izquierda), los Grupos Revolucionarios Socialistas (GRS; ligados al grupo marxista El Obrero) y la TUPAC. Sin embargo, hay un debate del FAUDI con estas tres aliadas y en especial con la TUPAC. Según los autores, LAP-GRS y TUPAC coinciden en que no se debe disputar la dirección de los organismos de masas tradicionales como la FUA y la Confederación General del Trabajo (CGT), y proponen centros elegidos por "métodos espontáneos, como la asamblea". Aquí RyC citan el documento del FAUDI que, además de rechazar ese modelo, sostiene que hay que mantenerse dentro de la FUA "con las banderas del Sitrac y el Sitram"; asimismo, "la alianza de organismos con la clase obrera sería más real porque incluiría a todos los estudiantes representados en las organizaciones de masas, es decir a la mayoría, y no solo a las tendencias de izquierda y sus activistas"("Declaración del FAUDI", s/d., en Los Libros, 21, 1971, p. 18). 


\section{ReVistg all PaVtg}

\} LA ACTIVIDAD DE LAS AGRUPACIONES - CELENTANO, A. \}

Para los autores, se trataría de ganar las direcciones de esos organismos estudiantiles hasta que se forme un instrumento político del proletariado y evitar que, por medio del espontaneismo (en el que cae también TUPAC), esos organismos puedan ser trasformados en "apoyo logístico de masas" de los grupos armados, como se supone que promovían GRS y LAP. RyC fijan los objetivos clave del bloque de izquierda estudiantil: la convergencia con "un producto -y proyecto político- de la clase obrera", en lo universitario con la definitiva superación del planteo eficientista y en lo orgánico con el avance hacia la reestructuración de la Federación Universitaria de Córdoba (FUC).

Como señalamos, los argumentos del artículo de RyC coinciden con los propuestos en las "Bases para el congreso del FAUDI" y en la propaganda de sus agrupaciones de base en diferentes regionales (Buenos Aires, Tucumán, Corrientes, La Plata, Rosario, Nordeste). En ese sentido, el número de la revista constituye un mirador privilegiado del proceso de radicalización realizado por el grupo intelectual reunido en la revista Los Libros.

Pero además veremos que permite iluminar los límites de la experiencia política que el artículo reivindica. En primer lugar, en el cuestionamiento a la Reforma del '18 el artículo adjudica el carácter liberal democrático a la condición pequeño burguesa del estudiantado; sin embargo, cuando se ocupa del crecimiento de la nueva izquierda estudiantil no atiende al condicionamiento de clase. En segundo lugar, el balance enfatiza la ruptura con el legado reformista por su carácter moderado; sin embargo, el texto - al igual que el documento del FAUDI - legitima los instrumentos organizativos y políticos instalados por la tradición de la Reforma (la asamblea, la movilización callejera, el centro y la federación) en tanto esos instrumentos se muestran como una vía para asegurar la masividad y evitar el espontaneismo que desembocaría en una nueva derrota. En ese sentido, tal vez había que reconocer que tanto esos instrumentos como la unidad obrero-estudiantil, reivindicados por los maoístas del FAUDI, se inscriben en nuevas prácticas (la insurrección, la construcción del Partido revolucionario y la impugnación del academicismo), a pesar de guardar importantes deudas con el legado reformista del ' 18.

El segundo límite que se podría señalar al planteo del texto es que tiene una mirada optimista sobre las luchas estudiantiles, mientras que en el momento de su publicación podía vislumbrarse cierto cierre de ese ciclo insurreccional y la consiguiente apertura del ciclo en el que prima el estado y la masiva adhesión de los universitarios al peronismo. El rol de Perón y de su movimiento en general es caracterizado por el FAUDI como un agente político que vendría - con poca posibilidad de éxito, según el FAUDI - a desviar y neutralizar la fuerza revolucionaria que desde el Cordobazo no cesa de hacerse presente. Bajo este análisis, a comienzos de 1972 el FAUDI y la TUPAC se enfrentan al GAN a través de un frente común que agita la consigna "ni golpe ni elección, revolución!". Pero ese 


\section{Revista pll paעtg}

\} LA ACTIVIDAD DE LAS AGRUPACIONES - CELENTANO, A. \}

frente común de los maoístas fracasa en su apuesta por mantener abierta la secuencia insurreccional, pues el estado ya ha logrado neutralizar la nueva secuencia, al tiempo que ha reintroducido la democracia en las instituciones preexistentes (partidos políticos, estructuras sindicales y empresariales, centros estudiantiles). Así, el Ilamado maoísta a no participar de las elecciones de 1973 repercute en la universidad produciendo el aislamiento de las tendencias maoístas. Éstas quedan en minoría dentro de una FUA ahora en manos del bloque formado por la alianza de la Franja Morada, el PC y otros grupos de la línea nacional.

Si bien no lo analizamos en este trabajo, a partir de 1974 el FAUDI y el PCR comienzan un viraje en sus posicionamientos políticos y especialmente los relativos al gobierno peronista. Este cambio se manifiesta en la adopción de la línea de defensa del gobierno de María E. Martínez de Perón y genera la ruptura de los acuerdos con TUPAC en la universidad y con VC a nivel nacional. El FAUDI seguirá participando en las disputas de las federaciones y los centros de estudiantes, pero no logrará incidir en la dirección del movimiento estudiantil como en los años anteriores y se encuentra enfrentado no sólo con la TUPAC, sino que -como veremos en los siguientes apartados- también es cuestionado por los otros grupos estudiantiles maoístas: el GEA y el GRE.

\section{3- El Grupo de Estudiantes Antimperialistas (GEA)}

Aunque el GEA se funda en 1971, su aparición debe considerarse como el punto de llegada de la militancia política sostenida por un núcleo de estudiantes universitarios durante la década del sesenta. En los primeros sesentas, Víctor y Juan Artigas, Ilda Luchini, el Vasco Inchaurraga, Jorge Benítez y Luis Paz se formaron en el Socialismo de Vanguardia, pasaron por la alianza con el peronismo, el apoyo al proyecto del Che en Bolivia y por diversos intentos de constituir el "partido revolucionario". Como otros grupos de la nueva izquierda, apoyaron la formación de la CGT de los Argentinos y, basándose en lo que entendían como "las lecciones del Viborazo", fundan el Partido Comunista Maoísta (PCM) y su periódico Nueva Democracia. El PCM organizó el GEA y el Grupo de Estudiantes Secundarios Antimperialistas (GESA) como sus frentes estudiantiles de masa. La tendencia aparece públicamente en las universidades de La Plata, Córdoba y Mar del Plata en diciembre de 1971.

Si bien la denominación de "grupo" era frecuente en el movimiento estudiantil, en el caso del GEA le sirve para diferenciarse del FAUDI y la TUPAC, consolidados como "frente" y "tendencia". El GEA combina su actuación en las aulas universitarias con el llamado a la unidad entre los estudiantes y los obreros clasistas; para ello se inspira, por un lado, en las acciones desplegadas por los guardias rojos en la revolución cultural 


\section{nevistg ell palla}

\} LA ACTIVIDAD DE LAS AGRUPACIONES - CELENTANO, A. \}

proletaria china y, por el otro, en la tradición antimperialista del reformismo, pero en el imperialismo a combatir agregan, junto al norteamericano, el de la Unión Soviética denunciado por los maoístas.

Las primeras intervenciones del GEA en La Plata se desarrollan a partir de las acciones de solidaridad con la huelga de los obreros de la planta textil Petroquímica Sudamericana en la ciudad de La Plata (BRETAL, 2008). Al frente del conflicto obrero se encuentra un cuerpo de delegados que reúne a activistas identificados con las diversas tendencias de la nueva izquierda, entre ellas la agrupación "Organización y Lucha", que integra a trabajadores y estudiantes proletarizados vinculados al PCM. Durante el conflicto, el GEA, junto con el FAUDI y la Tendencia Estudiantil Revolucionaria Socialista (TERS; ligada al grupo trostkista Política Obrera), impulsa el "fondo de huelga" y las reuniones de la Federación Universitaria de La Plata con los obreros de Petroquímica (BRETAL, 2008).

En 1972 el GEA cuenta con unos veinte militantes activos entre las facultades de Humanidades, Ingeniería, Bellas Artes, Medicina y Veterinaria de la Universidad de La Plata (UNLP), en esta última suma al ex presidente del centro de estudiantes, el "colorado" Daniel Bertoni. La actividad de agitación y propaganda del GEA, a la vez que aborda la problemática universitaria, concentra en la "unidad obrero estudiantil" sus expectativas de transformación de la sociedad y de la misma universidad. El GEA considera a los organismos gremiales (los centros y federaciones estudiantiles) como estructuras organizativas superadas por la aparición de los cuerpos de delegados, además de juzgarlas desbordadas por la combatividad de las masas, las que se encontrarían a las puertas de la insurrección general. Esto no impide que en la regional marplatense el GEA participe de la conducción de los centros estudiantiles, tal el caso de la Facultad de Arquitectura, en la que el GEA, encabezado por Guillermo García y Carlos Peychaux, gana la dirección del centro en 1971. Por entonces el centro encabeza las manifestaciones de protesta contra el asesinato de la estudiante de esa facultad, Silvia Filler, ejecutado por un grupo de la derecha nacionalista.

EI GEA entiende que la rebelión de los estudiantes e intelectuales debe converger con la lucha obrera - especialmente la callejera -, para ello prioriza como método la deliberación asamblearia y los actos relámpago. De allí que los militantes platenses de ese grupo hayan elegido como consigna para "hacer hablar" a las paredes del Comedor Universitario de la UNLP la siguiente amalgama de guevarismo y clasismo: “¡Formar uno, dos, cien Sitrac-Sitram!".

Al igual que el FAUDI y la TUPAC, el GEA cuestiona las expectativas que había depositado la izquierda en la salida electoral abierta por el GAN, denuncia las elecciones de 1973 como una trampa de la burguesía argentina para evitar el alzamiento revolucionario del pueblo. Sin embargo, como señalamos arriba, el vertiginoso crecimiento del peronismo en las casas de altos estudios y el paso a la lucha armada por parte de organizaciones 


\section{Revista pll paעtg}

\} LA ACTIVIDAD DE LAS AGRUPACIONES - CELENTANO, A. \}

revolucionarias con fuerte predicamento entre los estudiantes dejan escaso margen político para el GEA y otras tendencias que no apoyan esas opciones. Durante la "primavera camporista" de 1973, el GEA junto a la mayoría de los núcleos activos de la nueva izquierda participa en las tomas y ocupaciones de las facultades y enfrenta a las corrientes que se reivindicaban "reformistas": la Franja, el MNR y al MOR.

Entre 1973 y 1974 la mayoría de los militantes del GEA La Plata integran el PCM y, con la consigna de ser "chispa y puente" entre los estudiantes y la clase obrera se proletarizan en las fábricas de la zona: la petrolera estatal YPF, los Astilleros Rio Santiago y la metalúrgica OFA, entre otras. Por otra parte, varios militantes de la regional marplatense del GEA se proletarizan en la industria del pescado, la metalúrgica Eskabe y en empresas textiles. La decisión de ampliar la incidencia del partido en las fábricas es impulsada por el comité central del PCM (un organismo donde predominan los ex estudiantes universitarios, varios de ellos proletarizados desde los años sesenta), pero también los jóvenes universitarios que deben llevar adelante ese cambio en sus vidas acuerdan con la decisión. En pocos meses esta línea política puso de manifiesto numerosas dificultades, pues los militantes debían afrontar las duras condiciones de trabajo, enfrentar los métodos violentos de las direcciones sindicales tradicionales y eludir la persecución de los aparatos represivos parapoliciales.

A partir de 1974, en La Plata una serie de asesinatos producen una marca significativa en la vida política de la UNLP, al tiempo que imponen en la universidad el viraje a la derecha que se registra en el resto del país. En octubre de 1974 son asesinados los líderes sindicales de los trabajadores no docentes de la UNLP Rodolfo Achem y Carlos Miguel, alineados con la tendencia revolucionaria del peronismo, y en diciembre es acribillado en Berisso el militante maoísta Enrique Rusconi, dirigente de la FULP y del PCR. Ambos crímenes repercuten intensamente entre los activistas maoístas, a pesar de que estaban atravesados por crecientes divergencias. La más importante de esas divergencias era el hecho de que el FAUDI pretendía combinar las reivindicaciones estudiantiles con la defensa del gobierno peronista, eje de su política que llamaban "antigolpista", mientras que el GEA adjudicaba al gobierno peronista la responsabilidad de la operación represiva; ésta estaría especialmente impulsada por el ministro de Educación Oscar Ivanissevich.

Además, según el GEA, con la llamada "Misión Ivanissevich" el gobierno se habría propuesto terminar con el ingreso irrestricto, fijar cupos y un decálogo de condiciones exigidas a los inscriptos, entre ellas: buenas calificaciones en la secundaria y certificado de "buena conducta" otorgado por la policía. A ello se agregaba el intento de regionalizar al estudiantado según las "zonas de influencia" de cada universidad. (Nueva Democracia, 29 , febrero de 1975, p. 7 ). 


\section{ReVistg all pavtg}

\} LA ACTIVIDAD DE LAS AGRUPACIONES - CELENTANO, A. \}

Pocos meses después, a comienzos de 1975, el GEA señala en un panfleto que Ivanissevich reconoce que no habrá normalización en las universidades, afectadas por las suspensiones de actividades decretadas por los rectores. Para el GEA esas interrupciones en la actividad académica resultan de la crisis gubernamental y constituyen un "viraje de la gran burguesía" que ha adoptado una política universitaria elitista y confesional. Ese viraje no habría despertado la suficiente resistencia del movimiento estudiantil porque fue hábilmente implementado durante el receso, reconoce el panfleto. La iniciativa gubernamental afectaría especialmente

los aspectos democráticos, progresistas y antimperialistas que con la lucha consiguió el pueblo. Por eso en casi todas las universidades del país se han anulado las modificaciones a los planes de estudios producidas desde el 25 de mayo del '73. Eliminando los programas y las cátedras progresistas, marxistas y nacionales. ${ }^{6}$

En sus panfletos y declaraciones de 1975, el GEA intenta prescribir que el alto nivel de conciencia del pueblo hará fracasar la línea educativa del gobierno de la viuda de Perón, pero esta propaganda política no especifica las formas organizativas que permitirían frenar la iniciativa gubernamental y tiende a culminar con la formulación de imprecisos llamados a la unidad y a "superar las vacilaciones y la debilidad que acarrea la división" en el movimiento estudiantil. Por otra parte, a mediados de 1975, el GEA acusa al FAUDI y a otros grupos de impulsar el "reflujismo", en lugar de apostar a la ofensiva estudiantil. En esa acusación se apoya, por un lado, el entusiasmo del GEA ante la movilización estudiantil en apoyo a la multitudinaria rebelión obrera que forzó la caída del ministro Celestino Rodrigo en julio de 1975; por otro lado, en la lectura que hace el GEA de la caída delvanissevich (ella habría sido fruto de la movilización estudiantil y popular, y no tanto de la propia crisis del peronismo); y por último, en la realización de elecciones de centros de estudiantes, a pesar de la voluntad del gobierno. Para el GEA, tanto el rector de la UBA como los de la UNLP y la UNC adelantan el cierre del ciclo lectivo con el objetivo de dispersar al estudiantado y evitar las elecciones de los centros de estudiantes y el avance estudiantil.

Contradiciendo las expectativas del GEA, en el segundo semestre de 1975 disminuyó la movilización estudiantil en las universidades nacionales, a la vez que crecieron los asesinatos, las cesantías y las persecuciones a los docentes. En este proceso, las divergencias políticas y la parálisis organizativa predominan en un movimiento estudiantil que ahora se encuentra a la defensiva. Y también el GEA debe asumir una posición defensiva, ya que en julio de 1975 son detenidos los militantes de la regional marplatense

6 "La Misión Ivanissevich profundiza su ofensiva reaccionaria", panfleto del GEA, febrero de 1975. 


\section{Revista pll paעtg}

\} LA ACTIVIDAD DE LAS AGRUPACIONES - CELENTANO, A. \}

Carlos Lazzaro y Jorge Ubeda, y otros militantes sufren allanamientos policiales en sus domicilios

Para inicios de 1976, una parte de los militantes del GEA de La Plata, Mar del Plata y Córdoba están proletarizados mientras otros apoyan las pocas actividades de propaganda que se activan en las facultades, debido a la presencia represiva estatal y paraestatal. Siguiendo la política del PCM, el GEA sostenía que "La nueva dictadura militar tendrá su Cordobazo", y para impulsar la rebelión popular lanzaron una campaña de agitación en las facultades y en la puerta de las fábricas de la zona. En setiembre de 1976, fueron secuestrados Graciela Torrano, Abel Fucks, Alejandro De Sío y Domingo Cáceres, quienes distribuían panfletos en la puerta de la petrolera YPF. Al igual que el FAUDI, la TUPAC, el GRE y el resto de las organizaciones de la nueva izquierda de la universidad, el GEA pasó a integrar la "acción subversiva en el ámbito educativo" que los documentos de la inteligencia militar distribuyeron profusamente en escuelas y universidades durante la dictadura.

\section{4- Los Grupos de Resistencia Estudiantil (GRE)}

El proceso de formación del Partido Comunista Marxista Leninista (PCML) iniciado a mediados de los sesenta, tuvo origen en una célula de obreros platenses que rápidamente atrajo a un grupo de estudiantes universitarios. Fundado el partido en 1971, comienza la formación de "frentes de masas" como el que adopta el nombre de Grupos de Resistencia Estudiantil (GRE). El GRE tuvo presencia organizada en la UNLP desde 1973, en las facultades de Arquitectura, Ingeniería, Humanidades y Bellas Artes, además de militantes en Odontología y Medicina. También se formaron grupos en Córdoba y en la UBA, además de contar con militantes en Rosario, aunque de estas universidades no quedaron documentos o panfletos sobre sus actividades (CELENTANO, 2005).

Los militantes del GRE se incorporaban al PCML en una célula estudiantil luego de un proceso de discusión de las tesis partidarias. Entre ellas se incluía la reproducción de un documento chino sobre la historia del movimiento estudiantil de ese país ("A 30 años del movimiento del movimiento del 9 de diciembre", s/f, PCML) prologado por unas seis páginas firmadas por el partido argentino, donde se define la centralidad de la dirección del "Partido" y la necesidad de prepararse para la lucha militar.

En esta línea argumental el documento explica que debido al carácter pequeñoburgués de los universitarios y a falta de un "verdadero partido marxista leninista" que lo dirigiera, el activismo que históricamente desarrolló numerosas tendencias democráticas y progresistas, ha sido vacilante y desviado por el revisionismo, hacia la derecha; y por el izquierdismo, hacia el espontaneísmo. Para el PCML se trata de evitar que los estudiantes 


\section{ReVistg all paUtg}

\} LA ACTIVIDAD DE LAS AGRUPACIONES - CELENTANO, A. \}

y los intelectuales caigan en la lucha del "movimiento democrático por el movimiento mismo", lo que los lleva a la mera lucha académica y los separa de las masas populares. Los militantes maoístas deben tomar como base el movimiento democrático ya existente de los estudiantes y los intelectuales para darle un nuevo carácter. En este sentido el documento propone:

Transformar a los estudiantes e intelectuales democráticos, bajo la dirección del Partido, en intelectuales revolucionarios de nuevo tipo firmemente decididos a integrarse activamente en la lucha de nuestro pueblo... Transformar de este modo, el movimiento democrático en un semillero de jóvenes revolucionarios está indisolublemente ligado a poner al estudiantado bajo la dirección del Partido. (idem, p. 4)

Transformar a los estudiantes para transformar la lucha democrática producirá un nuevo tipo de intelectual, el intelectual revolucionario. Esta afirmación, frecuente entre los maoístas argentinos, replica localmente el deslizamiento promovido por los maoístas chinos en la concepción de la lucha ideológica durante la fase de la revolución cultural.

En el caso del PCML el partido funciona como dirección y fuerza de esa transformación si orienta y educa a los estudiantes en la acumulación de fuerzas y en la combinación de los métodos de lucha. Esta educación tiene como objetivo neutralizar el peso del reformismo y el culto a la espontaneidad de las masas que - según el PCML - pregonan los oportunistas en el movimiento estudiantil. La dirección del Partido dará una nueva perspectiva a la lucha académica y democrática de los estudiantes, para que sean verdaderos luchadores antifascistas y comunistas, basados en la experiencia mundial del "marxismo-leninismo", y también permitirá al partido preparar los contingentes estudiantiles para la lucha militar.

En la aplicación de esta línea político-ideológica, los GRE se diferenciaban de la TUPAC y el FAUDI por no participar con listas en las elecciones para los centros estudiantiles ni intervenir en la disputa específicamente académica. ${ }^{7}$ Especialmente debido a que el GRE caracterizaba un curso de fascistización de la situación política argentina desde principios de los años setenta, lo que exigía extremar la clandestinización de su actividad y la preservación de la identidad de sus militantes. Sin embargo, en algunas facultades los militantes del PCML fundaron el centro de estudiantes, como hicieran Walter Hernán Domínguez y Gladys Cristina Castro en la carrera de Arquitectura en la universidad privada de Mendoza. Además, el GRE reclutó algunos estudiantes secundarios en la zona platense y participó de las coordinadoras estudiantiles en las movilizaciones de 1975.

\footnotetext{
${ }^{7}$ Sin embargo, en algunas facultades los militantes del PCML fundaron el centro de estudiantes, como hicieran Walter Hernán Domínguez y Gladys Cristina Castro en la carrera de Arquitectura en la universidad privada de Mendoza.
} 


\section{Revista pll paעtg}

\} LA ACTIVIDAD DE LAS AGRUPACIONES - CELENTANO, A. \}

Es muy poca la información conservada sobre la acción de los GRE, más allá un puñado de volantes y el documento citado, que muestran una política de agitación, ya que fue diezmado por la dictadura y los sobrevivientes del PCML estaban concentrados en el frente sindical y político. El PCML fue ideado por núcleo obrero que rápidamente se nutrió de estudiantes universitarios luego se amplía sobre el reclutamiento juvenil que se partidiza y esa nueva militancia pasa por la proletarización. En el caso del PCML su rasgo específico es que fue la única organización que paso a la lucha militar, rasgo que de todos modos no diferenció de modo sustantivo el tipo de intervención universitaria que caracterizaba a los otros partidos y grupos maoístas hasta el golpe de estado.

Los trabajos de las agrupaciones estudiantiles y docentes del PCML se integraban, especialmente en las facultades y escuelas de la UNLP como Bellas Artes, el Colegio Nacional y el Liceo. Una docente universitaria que comenzó a militar a comienzos de 1975 describe el volanteo clandestino y su relación con Jorge Bonafini, activista del GRE. Los volantes y la entrevistas evidencian el grado de repliegue de esta tendencia maoísta y el aislamiento en que se encontraba sometido, apreciable en la ausencia de referencias a la movilización del estudiantado que por entonces a pesar de la represión estatal y paraestatal, mantuvo cierto margen de maniobra para las reuniones y la propaganda e inclusive la movilización callejera, como ocurrió con la lucha del "medio boleto obrero estudiantil".

La militancia del GRE continuó activando clandestinamente durante el primer año de la dictadura, propiciaban la organización clandestina para realizar el boicot contra las medidas limitacionistas que impusieron los militares en la UNLP. Pero su acción se restringió a las volanteadas y reuniones, que menguaron rápidamente debido a la creciente presencia militar en las aulas de la UNLP. Hacia fines de 1977 la mayoría de sus militantes fueron secuestrados y desaparecidos como gran parte de los integrantes del PCML.

\section{Conclusión}

En tanto la "Revolución Argentina" se propuso impulsar y garantizar el desarrollo capitalista argentino, necesitaba de los estudiantes como fuerza de trabajo intelectual en proceso de formación, e intentó imponer un proceso de modernización autoritaria en la universidad frente al cual el movimiento estudiantil se transformó en una de las fuerzas integrantes de la nueva oposición o nueva izquierda. Las nuevas formas de lucha estudiantil fueron generaron también un progresivo cuestionamiento a la UCR y el peronismo tradicional, y una ruptura con los viejos partidos de izquierda: el PC y el PS. Estos partidos eran considerados no solo "reformistas" o "burgueses", sino que además habrían demostrado su ineficacia para enfrentar 


\section{ReVistg all PaVtg}

\} LA ACTIVIDAD DE LAS AGRUPACIONES - CELENTANO, A. \}

al gobierno militar. Nuestra reconstrucción histórica sobre la formación de las corrientes estudiantiles maoístas permite identificar en un principio el importante papel que tuvieron estos grupos en la formación de la nueva izquierda en la universidad a fines de los sesenta. La TUPAC y el FAUDI y, en menor medida el GEA y los GRE formaron parte de la intervención política radicalizada que, junto a otras corrientes de la nueva izquierda, impulsó nuevos métodos de lucha y formas de organización para el enfrentamiento con la dictadura militar.

En este proceso se formaron los militantes estudiantiles maoístas, provenientes en su mayoría de las clases medias urbanas, que desarrollaron una crítica al legado ideológico, político y organizativo de la Reforma del '18. Desde fines de los sesenta los militantes izquierdistas insistieron en que la lucha dentro de la universidad contra el "limitacionismo" o el "cientificismo", junto con crítica a la sociedad capitalista y a la dictadura militar mostraran la necesidad de la intervención directa en la lucha política y una superación de las anteriores formas de participación estudiantil. En efecto, a partir del acontecimiento que significaron las insurrecciones desatadas desde mayo de 1969 estos estudiantes impulsaron las protestas callejeras masivas, la primacía de la deliberación de las bases mediante asambleas, la transformación en su relación con los profesores, la formación de cuerpos de delegados en cada facultad y de establecer acuerdos con las bases obreras rebeladas contra los tradicionales dirigentes sindicales, herramientas que le darían nueva efectividad a la acción antes concentrada en las direcciones de los centros y federaciones universitarias.

Además, desde fines de los sesenta, la mayoría de los agrupamientos de izquierda que se identifican con el maoísmo ya habían participado de la dirección de centros y federaciones estudiantiles y consideraron que ya no se trataba solo intervenir en los procesos de lucha insurreccional junto a los trabajadores y en el cuestionamiento de las instituciones universitarias como reproductoras del orden social capitalista. También se plantearon construir nuevos partidos comunistas (en medio de una profunda crisis de la experiencia comunista a nivel internacional), de elaborar programas y definir estrategias para la toma del poder, de organizar aparatos de prensa y propaganda, de construir células partidarias, constituir comités, prepararse para la lucha callejera y eventualmente armada. Asimismo, al plantearse la centralidad de la clase obrera en la lucha de clases, consideraron imprescindible ganar la dirección de las masas obreras y para ello no alcanzaba con la escasa inserción que cada grupo tenía en el movimiento obrero, lo que según sus posicionamientos ideológicos justificó el permanente proceso de proletarización de militantes universitarios hacia las fábricas de las grandes ciudades.

En la medida en que la mayoría de los grupos maoístas analizados reivindicaban la Ilamada "vía insurreccional" de carácter principalmente urbano, como vía para la toma del poder, tendieron a diferenciarse de 


\section{Revistg PII PaUtg}

\} LA ACTIVIDAD DE LAS AGRUPACIONES - CELENTANO, A. \}

otras tendencias de la nueva izquierda (como los Montoneros o el PRTERP) que construyeron organizaciones que tuvieran como tarea primordial la lucha armada. La primacía adjudicada por los maoístas a los movimientos insurreccionales masivos implicó que cuando el régimen militar organizara exitosamente una salida electoral en 1973, los partidos maoístas y sus tendencias estudiantiles se opusieron a la participación electoral mediante la cual el peronismo, que tenía mayoritario apoyo obrero, retornó al poder. Y esta transformación del régimen político mostró que la llamada vía insurreccional adoptada adolecía del límite que implica transformar un método de lucha en el centro de la política. 


\section{ReVistg all paUtg}

\} LA ACTIVIDAD DE LAS AGRUPACIONES - CELENTANO, A. \}

\section{Referencias}

BADIOU, A. Compendio de metapolítica. Buenos Aires: Prometeo, 2010 BONAVENA, P.; CALIFA, J. S.; MILLÁN, M. (2007), El Movimiento estudiantil argentino. Carrera de Sociología: Buenos Aires, 2007.

. "El cuerpo de delegados como forma organizativa del movimiento estudiantil. El 'doble poder' en la Facultad de Filosofía y Letras de la UBA. Lucha de Clases, 1 oct. 1997, p. 34-55.

BUCHBINDER, P. Historia de la universidad argentina. Buenos Aires: Sudamericana, 2005.

BREGA, J. ¿Ha muerto el comunismo? El maoísmo en la Argentina, conversaciones con Otto Vargas. Buenos Aires: Agora, 1990.

BRETAL, E. Experiencias de organización y lucha sindical en el Gran La Plata: el caso des Petroquímicas Sudamericanas, 1969-1973. Tesina de Licenciatura en Sociología, 2008, FaHCE-UNLP. Disponible en: http://www.me moria.fahce.unlp.edu.ar/tesis/te.501/te.501.pdf. Acceso: 10 mayo 2009.

BURGOS, R. Los gramscianos argentinos: cultura y política en la experiencia de pasado y presente. Buenos Aires: Siglo XXI, 2004.

CEBALLOS, C. Los estudiantes universitarios y la política. Buenos Aires: CEAL, 1985.

CELENTANO, A. Maoísmo y lucha armada: el Partido Comunista Marxista Leninista. En Lucha Armada, 4, 2005, p. 34-45. . Los libros, una lectura política. VI Jornadas Centro de Investigaciones de la Cultura de Izquierdas (CEDINCI). Buenos Aires, 2007.

Unidad obrero estudiantil. La nueva izquierda y las proletarizaciones de las corrientes maoístas en Argentina. En: Los trabajos y los días, 1. La Plata, 2009, p. 27-68.

Los libros y el concepto de "trabajador de la educación. XII Jornadas Interescuelas de Historia. Catamarca, 2011.

COLECTIVO EMILIO JAUREGUI. La generación del 70, sus ideas, militancia, aciertos y errores. Vida y luchas de Vanguardia Comunista. II parte. Buenos Aires, Nuevos Tiempos, 2009.

CRENZEL, E. El Tucumanazo. Buenos Aires: CEAL, 1991.

CRESPO, H. En torno a Cuadernos de Pasado y Presente. 1968-1983. En HILB, C. (Comp.). El político y el científico. Buenos Aires: Siglo XXI, 2011, p. 169-195.

FERRERO, R. Historia crítica del movimiento estudiantil en Córdoba, Tomo III (1955-1973). Córdoba: Alción, 2009. 


\section{Revista pll paעtg}

\} LA ACTIVIDAD DE LAS AGRUPACIONES - CELENTANO, A. \}

FRANCO, M. Un enemigo para la nación. Orden interno, violencia y 'subversión' 1973-1976. Buenos Aires: Fondo de Cultura Económica, 2011.

GILBERT, I. La Fede. Alistándose para la revolución. La Federación Juvenil Comunista 1921-2005. Buenos Aires: Sudamericana, 2009.

GORDILLO, M.; BRENNAN, J. Cordobazo, el clasismo y la movilización social. La Plata: De la campana, 2009.

KROTSCH, P. La universidad cautiva. La Plata: Al margen, 2002.

MILLAN, M. De la lucha de calles a la lucha en los claustros: el movimiento estudiantil de Córdoba entre el Cordobazo y la 'primavera camporista' (jun 1969 - mayo 1973). Conflicto Social, 9, junio de 2013. Disponible en línea: <http://webiigg.sociales.uba.ar/conflictosocial/revista/09/09_ M.Millan.pdf>. Acceso: 8 dec. 2013.

O'DONNEL, G. El estado burocrático autoritario Buenos Aires: Belgrano, 1982.

ORBE, P. La política y lo político en torno a la comunidad universitaria bahiense (1956-1976). Estudio de grupos, ideologías y producción de discursos. Mimeo. 2010.

PORTANTIERO, J. C. Estudiantes y política en América Latina. El proceso de la reforma universitaria (1918-1938). México: Siglo XXI, 1978.

PUCCIARELLI, A. (Ed.) La primacía de la política. Lanusse, Perón y la Nueva Izquierda en tiempos del GAN. Buenos Aires: Eudeba, 1999.

RAMIREZ, A. J. Tucumán 1965-1969: movimiento azucarero y radicalización política, Nuevo Mundo Mundos Nuevos, Débats, jul. 2008. Disponible en: <http://nuevomundo.revues.org/38892>. Acceso: 10 jul. 2014.

TARCUS, H. Diccionario biográfico de la izquierda argentina (De los anarquistas a la nueva izquierda, 1870-1976). Buenos Aires: Emece, 2007.

TORTTI, M. C. Protesta social y Nueva Izquierda durante el Gran Acuerdo Nacional. En: PUCCIARELLI, A. (ed.) La primacía de la política. Lanusse, Perón y la Nueva Izquierda en tiempos del GAN. Buenos Aires: Eudeba, 1999, p. 205-234.

. El viejo partido socialista y los orígenes de la nueva izquierda.

Buenos Aires: Prometeo, 2009.

Recebido em 18 de agosto de 2014.

Aprovado para publicação em 22 de agosto de 2014. 